\title{
A STEM study of glass
}

\author{
J. Silcox and K.A. Mkhoyan \\ School of Applied and Engineering Physics, Cornell University, Ithaca NY 14853
}

The Chicago group led by Albert Crewe invented the modern STEM by developing the field emission gun and adding a high quality objective lens [1]. Individual atom images demonstrated the validity of the approach [2]. EELS was an integral part of the initial idea in order to add chemical details as part of the instrument tool array. In the intervening years, STEM/EELS has become an increasingly vital component of the tools available to the electron microscopist. With the emergence of aberration correction this tool will become even more valuable. In this talk, we discuss STEM/EELS studies [3] of a silicate glass that provide rich nanoscale detail that would have been difficult to acquire prior to the invention of STEM.

The system is a $\left(\mathrm{CaO}-\mathrm{Al}_{2} \mathrm{O}_{3}\right)_{0.9}-\left(2 \mathrm{SiO}_{2}\right)_{0.1}$ glass. Silicate glasses can be readily damaged by electron beams [4] and the damage is normally considered irreversible. In this case the chemical changes observed resulted in an apparently complete reversal of electron beam damage in a silicate-based glass system at ambient temperature. Composition sensitive ADF images taken before and after damage and during recovery are presented in Figs. 1(a-d). Here 2 min. of extensive electron-beam-induced damage was applied to a small area and then recovery was monitored at $30 \mathrm{sec}$ intervals. It took only $2 \mathrm{~min}$ for the sample to fully recover. The intensity of the ADF signal drops dramatically indicating heavy mass loss in the damaged area. Its accumulation in neighboring areas is apparent when the difference in ADF signals, recorded before and after damage, is obtained. The total ADF signal calculated by integrating the intensities of the images (a) and (b), recorded before and after damage, proved to be the same suggesting that there has been no loss of total mass within detection limits.

For detailed compositional and structural analysis, core-level EELS was used. Fig. 2 shows changes in the EELS spectra of the $\mathrm{Ca} \mathrm{L}_{2,3}$ and $\mathrm{O} \mathrm{K}$-edges with progressive damage. A significant reduction of the intensity of the $\mathrm{Ca} \mathrm{L}_{2,3}$-edge occurred but no visible changes in the fine structure was observed. In contrast, the fine structure of the $\mathrm{O} \mathrm{K}$-edge undergoes dramatic changes with damage. A new peak appears at $\sim 531 \mathrm{eV}$ indicating that a significant amount of molecular oxygen $\left(\mathrm{O}_{2}\right)$ [4] is formed in the damaged area. The EELS spectra recorded after recovery show that the fine structure as well as the intensities of $\mathrm{Ca}_{2,3}$ and $\mathrm{O} \mathrm{K}$-edges are fully restored.

Fig. 3 (a) shows the recorded EELS spectra of the $\mathrm{Al} \mathrm{L}_{2,3}$-edge measured from this glass and also, for comparison, from amorphous $\mathrm{Al}_{2} \mathrm{O}_{3}\left(\mathrm{a}-\mathrm{Al}_{2} \mathrm{O}_{3}\right)$. Comparison of these two spectra shows that the $\mathrm{L}_{2,3}$-edge measured in the undamaged glass has more and better defined peaks (BE) than in a- $\mathrm{Al}_{2} \mathrm{O}_{3}$. Briefly put, disordered solids exhibit very little fine structure in EELS spectra whereas solids with crystalline order exhibit sharp features in the fine structure of the core-edges. We can, therefore, argue that the coordination number of the $\mathrm{Al}$ atoms in the undamaged glass is higher than in $\mathrm{a}-\mathrm{Al}_{2} \mathrm{O}_{3}$ suggesting order, perhaps paracrystallinity, of the glass network. Bouchet and Colliex [5] report that higher the coordination of the $\mathrm{Al}$ in different $\mathrm{Al}_{2} \mathrm{O}_{3}$ compositions the finer is the structure of the $\mathrm{L}_{2,3}$-edge spectrum (with a bigger number of peaks). In damaged glass, as can be seen from Fig. 3 (b), the $\mathrm{Al}$ spectrum is close to that of a- $\mathrm{Al}_{2} \mathrm{O}_{3}$.

Since the damaged system reverts to a condition identical with the initial condition, we conclude that the initial thermodynamic state of the glass is a very deep energy minimum. The observations suggest that non-glass forming elements are able to move surprisingly long distances $(\sim 10 \mathrm{~nm})$ in the glass at room temperature under the influence of a high electrostatic field and that the recovery level depends on the way in which the glass handles excess oxygen [6]. 
[1] J. Wall, J. Langmore, M. Isaacson, and A.V. Crewe, PNAS 71, 1 (1974).

[2] A.V. Crewe, J. Wall and J. Langmore, Science 168, 1338 (1970).

[3] K.A. Mkhoyan, J. Silcox, A. Ellison, D. Ast, R. Dieckmann, submitted for publication.

[4] N. Jiang, J. Qiu, A. Ellison and J. Silcox, Phys. Rev. B 68, 064207 (2003).

[5] D. Bouchet and C. Colliex, Ultramicroscopy 96, 139 (2003).

[6] This work is supported primarily by the Nanoscale Science and Engineering Initiative of the NSF EEC-0117770 and NYSTAR C020071. The sample preparation facilities and STEM are supported by NSF through the Cornell Center of Materials Research DMR 9632275. The technical support of M. Thomas is also acknowledged.
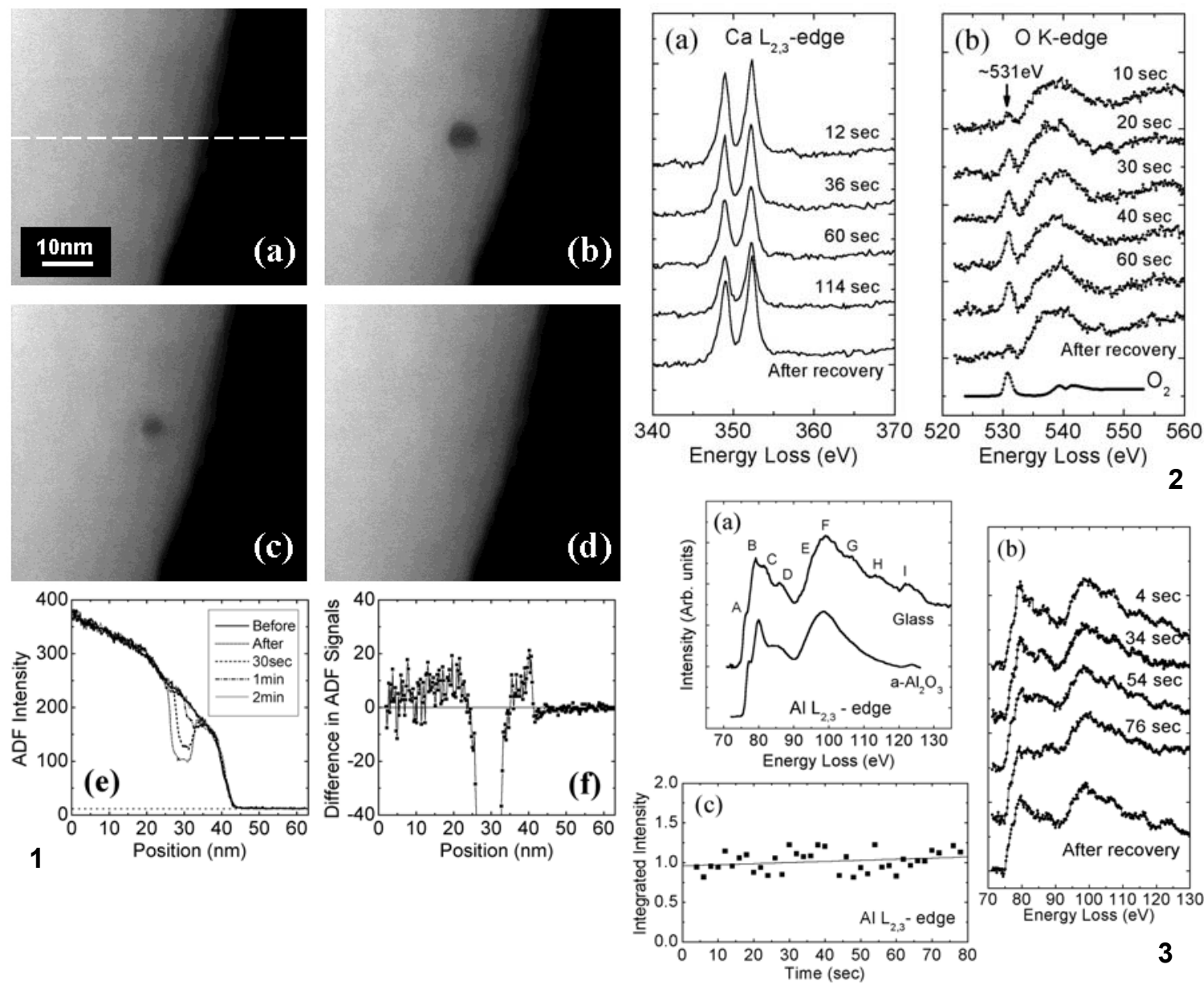

FIG. 1. ADF images of glass particle. (a) Before the damage, (b) after 2 min. of electron beam damage (only $6.3 \times 6.3 \mathrm{~nm}^{2}$ area was damaged); (c-d) images recorded after $30 \mathrm{sec}$. and $2 \mathrm{~min}$. of recovery with beam turned off; (e) line scans of the ADF intensities across the same damaged area (dashed line in (a)) from images (a), (b), (c) and (d); (f) Difference between line scans from (b) and (a).

FIG. 2. Evolution of the spectra of (a) $\mathrm{Ca}_{2,3}$-edge and (b) $\mathrm{O} \mathrm{K}$-edge with damage. The bottom spectra in (c) and (d) were recorded after recovery of sample, having beam off for 2 min.

FIG. 3. (a) Measured EELS spectra of the $\mathrm{Al}$ and $\mathrm{Si} \mathrm{L}_{2,3}$-edges, (b) evolution of this spectra with continuous damage and the recovery after 2 min. (c) Integrated intensity of the $\mathrm{Al} \mathrm{L}_{2,3}$-edge with continuous damage 